\title{
IMPLEMENTASI ELECTRONIC RELATIONSHIP MANAGEMENT (E- CRM) PADA BEAUTY KARLINA SALON UNTUK MENINGKATKAN LOYALITAS DAN MENARIK PASIEN BARU
}

\author{
Sarita Fabriani ${ }^{1)}$, Safitri Juanita ${ }^{2)}$ \\ ${ }^{1}$ Sistem Informasi, Fakultas Teknologi Informasi, Universitas Budi Luhur \\ ${ }^{1,2} \mathrm{Jl}$. Raya Ciledug, Petukangan Utara, Kebayoran Lama, Jakarta Selatan 12260 \\ E-mail : saritafabriani@gmail.com ${ }^{1)}$, safitri.juanita@budiluhur.ac.id ${ }^{2)}$
}

\begin{abstract}
Abstrak
Banyak perusahaan menggunakan banyak cara dalam strategi untuk mengembangkan usaha mereka, salah satunya adalah melalui layanan customer. Beauty Karlina Salon merupakan salah satu layanan jasa kecantikan yang berusaha memberikan kualitas produk dan layanan untuk perawatan kulit yang sehat, aman, dan terpercaya. Masalah yang didapat dalam penelitian ini adalah belum efektifnya penanganan dan penyampaian komplain, tidak ada testimonial dari pasien lain dan kurang efektifnya media promosi yang digunakan mengakibatkan lokasi usaha kurang dikenali, sehingga usaha ini perlu memanfaatkan penggunaan teknologi informasi secara maksimal dengan ditambahnya suatu media yang dapat mengelola hubungan antara perusahaan dengan pasien yaitu mengaplikasikan konsep Electronic Customer Relationship Management (eCRM). Pengaplikasian sistem e-CRM ini dibangun dengan pemrograman PHP dan database MySQL. Hasil dari penelitian ini terdapat beberapa fitur e-CRM yaitu fitur promosi, tukar poin, testimonial dan penanganan komplain sehingga dapat meningkatkan loyalitas pasien dan menarik pasien baru untuk datang ke Beauty Karlina Salon.
\end{abstract}

Kata kunci: Electronic Customer Relationship Management, loyalitas, menarik pasien baru, Salon.

\section{PENDAHULUAN}

Salon Kecantikan adalah tempat untuk merawat kecantikan seperti merias wajah, menata rambut, dan sebagainya. Bisnis salon merupakan bisnis yang menjanjikan, karena setiap orang ingin selalu tampil menarik. Di salon, dapat merawat kecantikan diri dan memanjakan diri dengan berbagai layanan jasa yang disediakan. Salon menawarkan berbagai macam jasa dengan tarif dan fasilitas di setiap salon. [1]

Beauty Karlina Salon merupakan salah satu usaha yang bergerak dalam bidang jasa kecantikan beralamatkan di Ruko Botanical Junction I10 / 31, Jl. Joglo Raya. Salon Beauty Karlina telah berdiri sejak tahun 2011. Jasa yang ditawarkan adalah perawatan kulit. Beauty Karlina Salon berusaha memberikan kualitas produk dan layanan untuk perawatan kulit yang sehat, aman, dan terpercaya. Untuk menjalani komitmennya dan dapat mengatasi masalah bisnis yang dihadapi seperti dalam hal kurang efektifnya media promosi yang digunakan mengakibatkan lokasi usaha kurang dikenali, maka usaha ini perlu memanfaatkan penggunaan teknologi informasi secara maksimal dengan ditambahnya suatu media yang dapat mengelola hubungan antara perusahaan dengan pasien yaitu mengaplikasikan konsep Electronic Customer Relationship Management (e-CRM).

CRM merujuk pada software sistem yang membantu perusahaan memperoleh dan menyimpan data pelanggannya serta melakukan hubungan dua arah. Tetapi saat ini CRM lebih menekankan pada perubahan kebijakan dan prosedur yang didesain untuk meningkatkan sales dan customer retention di berbagai lini perusahaan. Oleh karena itu, dalam tulisan ini penulis akan membahas apa yang dimaksud dengan CRM dan tujuannya, mengapa perusahaan perlu CRM, aplikasi CRM dalam industri manufaktur dan jasa serta kesimpulan yang dapat ditarik dari pembahasan CRM ini. [2]

Electronic Customer Relationship Management (e-CRM) merupakan suatu metode dalam mengelola relasi antara perusahaan dengan pelanggan dalam rangka peningkatan loyalitas pengkonsumsian produk-produk atau jasa yang ditawarkan oleh perusahaan dengan memanfaatkan media elektronis. Dengan adanya e-CRM ini pihak perusahaan dapat mengintegrasikan dan mengotomatisasi proses layanan pelanggan dalam bidang penjualan, pemasaran, dan layanan produk atau jasa yang berkaitan dengan perusahaan. [3]

Aplikasi ini bertujuan agar dapat memperhatikan bentuk layanan prima kepada pasien dan keinginan pasien sehingga dapat memberikan pelayanan lebih baik agar dapat membantu dalam menjaga loyalitas pasien. Serta diharapkan dapat meningkatkan komunikasi yang baik antara pasien dengan layanan jasa kecantikan Beauty Karlina.

Dengan melihat permasalahan yang didapatkan pada Beauty Karlina Salon, maka penulis 
mengangkat topik Eletronic Customer Relationship Management ini sebagai bahan penelitian dengan judul "Penerapan Sistem Electronic Customer Relationship Management dalam meningkatkan loyalitas serta menarik pasien baru pada Beauty Karlina Salon”.

Adapun beberapa penelitian sebelumnya yang membantu penulis dalam menyelesaikan penelitian ini yaitu, hasil penelitian dari Abdurrahman et al. [4] yang berjudul Impelementasi Customer Relationship Management (CRM) Pada Penerimaan Siswa Baru (Studi Kasus di Pondok Pesantren Darussalam Kabupaten Garut). Penelitian tersebut membahas tentang membangun sistem e-crm guna mempermudah bagi siswa dalam melakukan pendaftaran dan panitia dalam melakukan proses seleksi pada Penerimaan Siswa Baru dengan melakukan wawancara dan studi pustaka sebagai metode pengumpulan data. Perancangan sistem usulan menggunakan Flowmap, Context Diagram, Data Flow Diagram (DFD), Entity Relationship Diagram (ERD) dan sebagainya. Perbedaan penelitian ini dengan penulis adalah metode yang digunakan untuk mengumpulkan data dan cara desain perancangan sistem.

Selain itu, terdapat juga penelitian yang dilakukan oleh Babar dan Saitakela [5], dengan judul Implementasi Customer Relationship Management (CRM) Pada Klinik Valerie Beauty yang membahas penerapan CRM melalui website layanan informasi Valerie Beauty Clinic yang dibangun, dapat memudahkan pelanggan baru dan pelanggan lama dalam memperoleh informasi atau hal-hal terbaru mengenai Valerie Beauty Clinic Kupang baik berupa perawatan kecantikan maupun produk baru dan promo dari klinik. Perbedaan dari penelitian sebelumnya dengan penelitian penulis adalah metode dalam pengambilan data hanya melalui wawancara dan observasi.

\section{METODE PENELITIAN}

Berikut merupakan urutan langkah-langkah penelitian serta identifikasi dalam kegiatan dan perancangan yang dilakukan di Beauty Salon Karlina dapat dilihat pada Gambar 1

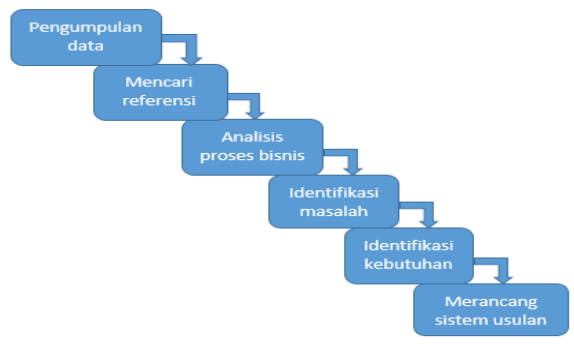

Gambar 1. Tahapan Penelitian
Dalam penelitian ini, terdapat beberapa proses yang dilakukan dalam identifikasi kebutuhan pada Beauty Salon Karlina diantaranya adalah penulis melakukan pengumpulan data yang merupakan tahapan awal dari penelitian yang dilakukan pada Beauty Salon Karlina. Lalu pada tahap selanjutnya melakukan pencarian referensi yang berkaitan dengan penelitian sebelum menganalisa proses bisnis yang sedang berjalan pada Beauty Salon Karlina. Kemudian penulis mengidentifikasi masalah pada proses bisnis berjalan yang digambarkan dengan Fishbone Diagram.

Fishbone Diagram atau Cause and Effect Diagram merupakan sebuah diagram yang digunakan untuk mengidentifikasi penyebab dan efek masalah. Diagram ini juga digunakan sebagai alat analisis dalam manajemen proyek (khususnya dalam management resiko) dan quality control. [6]

Kemudian mengidentifikasi kebutuhan dengan pemodelan data yaitu Entity Relationship Diagram. ERD (Entity Relationship Diagram) adalah model teknik pendekatan yang menyatakan atau menggambarkan hubungan suatu model. Di dalam hubungan ini tersebut dinyatakan yang utama dari ERD adalah menunjukan objek data (Entity) dan hubungan (Relationship), yang ada pada Entity berikutnya. [7]

Tahapan terakhir yaitu membuat rancangan sistem Electronic Customer Relationship Management (E-CRM) menggunakan metode pengembangan Waterfall.

Pemerolehan data melalui beberapa metode yaitu sebagai berikut. (a) Observasi pada penelitian ini dilakukan pada Salon Beauty Karlina selama beberapa waktu di di Ruko Botanical Junction I10 / 31, Jl. Joglo Raya. (b) Wawancara dilakukan dengan Ibu Lisa selaku staff. (c) Analisa Dokumen yang dibutuhkan dan diperoleh dari Salon Beauty Karlina yaitu brosur (status WhatsApp), pendaftaran data pasien serta history treatment atau diagnosa pasien. (d) Studi Kepustakaan pada penelitian ini diambil dari beberapa jurnal dan buku yang sesuai dengan permasalahan yang diteliti. Selain itu juga mencari informasi tambahan melalui internet.

\section{HASIL DAN PEMBAHASAN}

\subsection{Analisa Sistem Berjalan}

Gambar 2 adalah proses bisnis berjalan dengan Rich Picture pada Beauty Karlina Salon. 


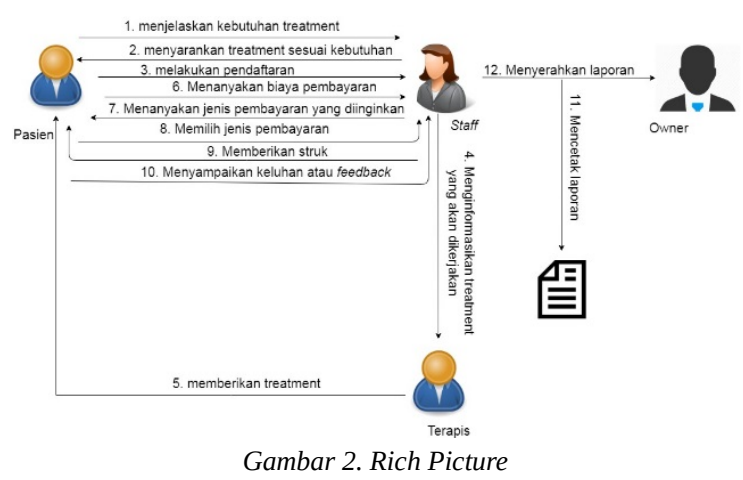

Berikut uraian dari rich picture:

1. Calon pasien datang ke salon dan menjelaskan kebutuhan treatment.

2. Staff menjelaskan dan menyarankan treatment atau diagnosa kepada pasien sesuai dengan kebutuhan.

3. Setelah pasien telah memilih treatment, pasien melakukan pendaftaran.

4. Staff menerima pendaftaran pasien kemudian memberitahukan kepada terapis mengenai treatment yang harus dikerjakan.

5. Terapis memberikan treatment kepada pasien yang sesuai informasi dari staff.

6. Setelah treatment selesai, pasien menanyakan biaya pembayaran.

7. Staff memberitahukan total dan jenis pembayaran.

8. Pasien memilih jenis pembayaran dan melakukan pembayaran.

9. Staff menerima pembayaran lalu mencetak bukti pembayaran (struk).

10. Pasien menyampaikan feedback kepada staff.

11. Setiap periode, staff membuat dan mencetak laporan pendaftaran.

12. Staff menyerahkan laporan yang telah dicetak kepada owner.

3.1. Analisis Masalah

Menganalisis masalah dengan fishbone dapat dilihat pada Gambar 3.

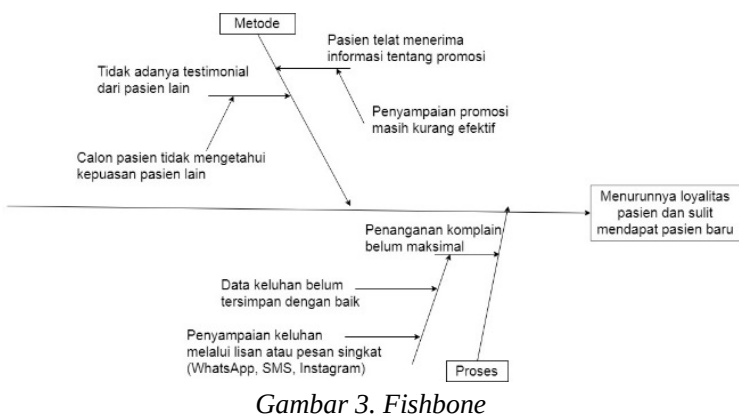

Berikut merupakan penjelasan dari fishbone di atas:
Tabel 1. Fishbone

\begin{tabular}{|c|c|c|c|}
\hline No. & Faktor & Sebab & Akibat \\
\hline 1. & Faktor Metode & $\begin{array}{l}\text { Kurang efektifnya } \\
\text { penyampaian } \\
\text { informasi mengenai } \\
\text { promo. }\end{array}$ & $\begin{array}{l}\text { pasien telat dan } \\
\text { terkadang salah } \\
\text { menerima tentang } \\
\text { promo yang } \\
\text { ditawarkan. }\end{array}$ \\
\hline 2. & Faktor Metode & $\begin{array}{l}\text { Tidak ada } \\
\text { testimonial dari } \\
\text { pasien lain. }\end{array}$ & $\begin{array}{l}\text { Calon pasien tidak } \\
\text { mengetahui review } \\
\text { dari pasien lain. }\end{array}$ \\
\hline 3. & Faktor Proses & $\begin{array}{l}\text { Penyampaian } \\
\text { komplain melalui } \\
\text { lisan atau pesan } \\
\text { singkat. }\end{array}$ & $\begin{array}{l}\text { Penanganan } \\
\text { komplain yang } \\
\text { masih belum } \\
\text { maksimal dan } \\
\text { penyimpanan data } \\
\text { komplain tidak } \\
\text { tersimpan dengan } \\
\text { baik. }\end{array}$ \\
\hline
\end{tabular}

\subsection{Analisis Sistem Usulan}

Pada tahap ini, peneliti melakukan analisis sistem usulan dengan menggunakan use case diagram.

a. Use Case Diagram Package Account

Gambar 4 ini menjelaskan bahwa user dimiliki oleh dua aktor yaitu pasien dan staff. Dalam package account, user dapat melakukan proses login.

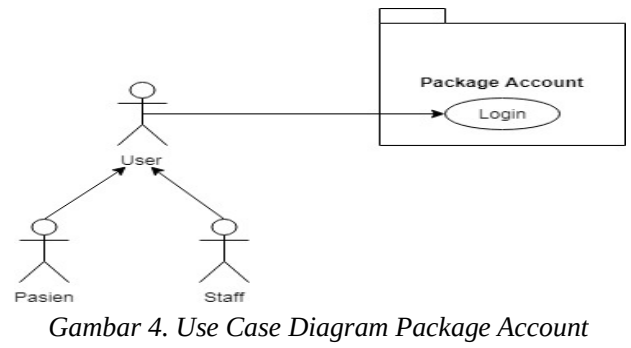

b. Use Case Diagram Master User Staff

Gambar 5 terdiri dari staff dapat entry pasien, view pasien, entry data diagnosa, view data diagnosa dan entry promo. Pasien dapat melihat data diagnosa dan promo.

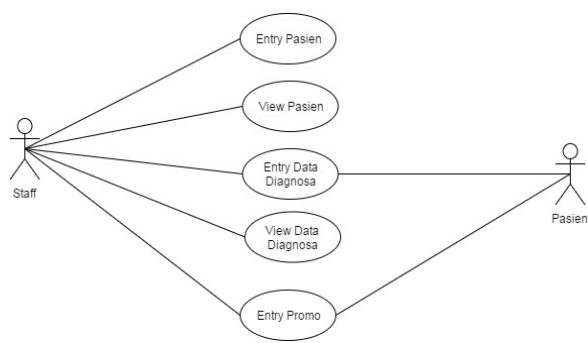

Gambar 5. Use Case Diagram Master User Staff

c. Use Case Diagram Transaksi

Pada Gambar 6 use case diagram transaksi user staff terdiri dari entry pendaftaran, view pendaftaran, entry kunjungan, view kunjungan, entry pembayaran, view pembayaran dan tanggapi 
komplain include dari user pasien yang terdiri entry komplain, entry testimonial, view testimonial, live chat dan tukar poin.

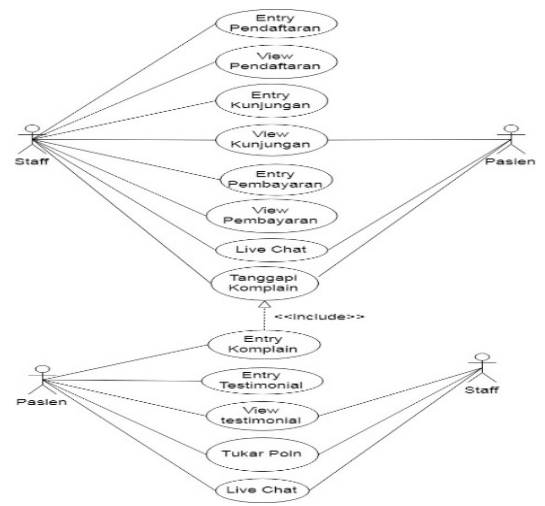

Gambar 6. Use Case Diagram Transaksi

d. Use Case Diagram Laporan

Gambar 7 menjelaskan kegiatan staff mencetak laporan pendaftaran, laporan pembayaran, laporan kunjungan, laporan pasien, laporan komplain, laporan testimonial, laporan tukar poin promo.

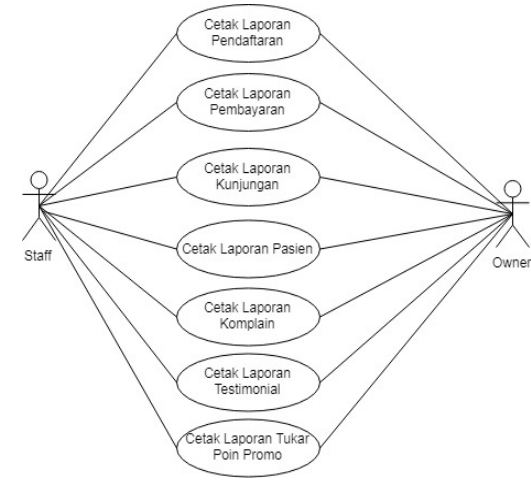

Gambar 7. Use Case Diagram Laporan

\subsection{Pemodelan Data}

a. Entity Relationship Diagram

Gambar 8 merupakan pemodelan data dengan ERD pada Beauty Karlian Salon.

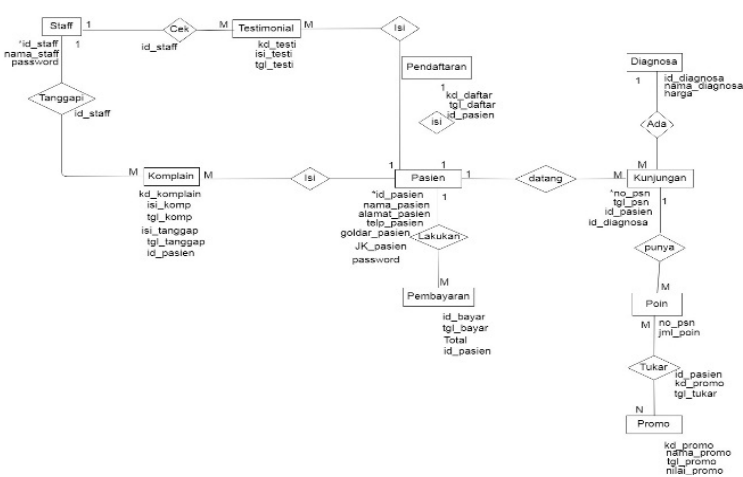

Gambar 8. Entity Relationship Diagram

\subsection{Implementasi Program}

a. Struktur Menu Halaman Awal

Gambar 9 merupakan struktur Menu usulan halaman admin pada website Beauty Karlina Salon

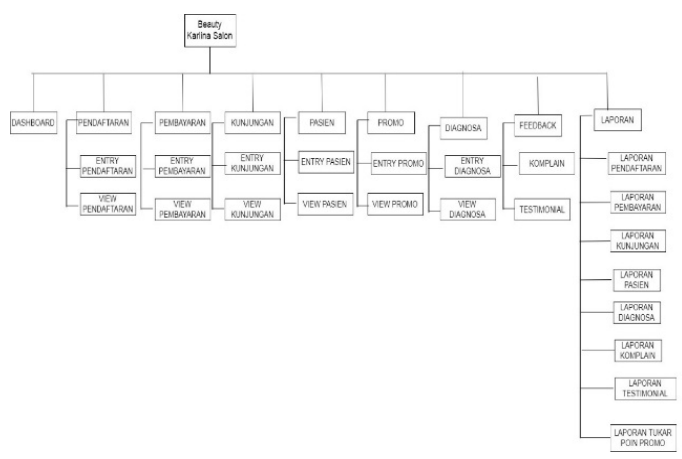

Gambar 9. Struktur Menu Halaman Admin

b. Tampilan Layar Halaman Awal

Gambar 10 menampilkan rancangan layar usulan pada halaman awal ketika pasien mengunjungi website Beauty Karlina Salon.

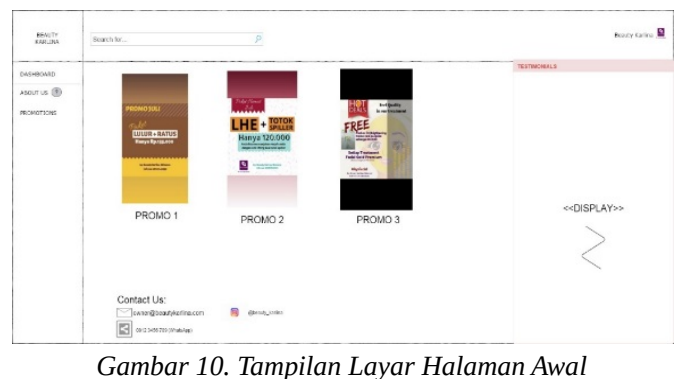

c. Tampilan Layar Entry Promo

Gambar 11 adalah tampilan layar untuk mengentri promo.

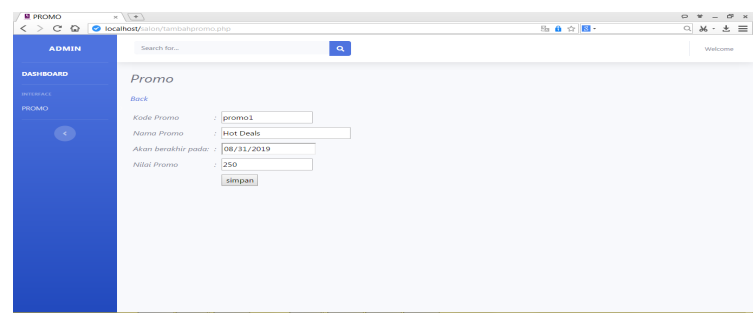

Gambar 11. Tampilan Layar Entry Promo

d. Tampilan Layar Tukar Poin Gambar 12 adalah tampilan layar tukar poin.

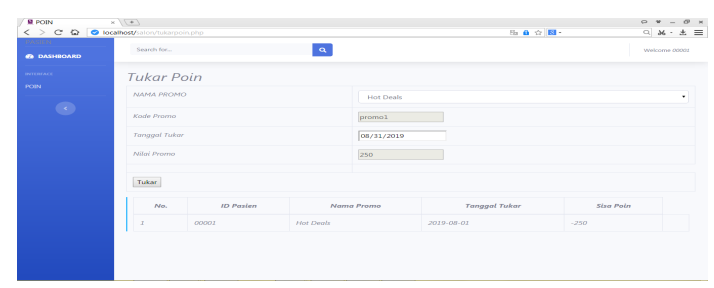

Gambar 12. Tampilan Layar Tukar Poin 
e. Tampilan Layar Laporan Tukar Poin

Gambar 13 menampilkan Tampilan Layar Laporan Tukar Poin Promo

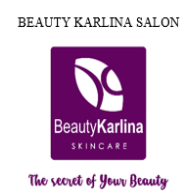

LAPORAN TUKAR POIN PROMO

\begin{tabular}{|c|c|c|c|c|c|}
\hline No. & $\begin{array}{c}\text { ID } \\
\text { Pasien }\end{array}$ & $\begin{array}{c}\text { Nama } \\
\text { Pasien }\end{array}$ & $\begin{array}{c}\text { Kode } \\
\text { Promo }\end{array}$ & Nama Promo & $\begin{array}{c}\text { Tanggal } \\
\text { Tukar }\end{array}$ \\
\hline 1. & 00001 & Silmia & Promo1 & Hot Deals & $2019-08-01$ \\
\hline
\end{tabular}

Gambar 13. Tampilan Layar Laporan Tukar Poin Promo

\section{f. Tampilan Layar Laporan Testimonial}

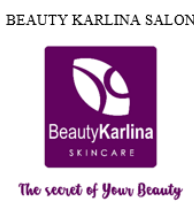

LAPORAN TESTIMONIAL

\begin{tabular}{|c|c|c|c|}
\hline No. & ID Pasien & Testimonial & Tanggal \\
\hline 1. & 00001 & Bagus. & $2019-08-01$ \\
\hline
\end{tabular}

Gambar 14. Tampilan Layar Laporan Testimonial

\subsection{Latar Belakang}

\section{KESIMPULAN}

Berdasarkan penelitian yang telah dilakukan dalam meningkatkan serta menarik pasien baru pada Beauty Karlina Salon, maka dapat diambil kesimpulan sebagai berikut.

a. Dengan adanya laporan data komplain dan laporan testimonial dapat sangat membantu dalam pelayanan terhadap pasien agar dapat menjaga dan meningkatkan loyalitas pasien. Dapat dijadikan sebagai tolak ukur untuk perkembangan perusahaan ke depan.

b. Dengan adanya aplikasi E-CRM dengan fitur dapat melihat testimonial dari pasien lain dapat menarik ketertarikan calon pasien baru

c. Mencetak laporan tukar poin promo dapat membantu dalam menentukan pemilihan promosi apa yang dapat diberikan untuk periode selanjutnya serta menampilkan fitur promosi pada halaman awal.

Adapun saran penulis kepada pengelola Beauty Karlina Salon adalah sebagai berikut.

a. Penerapan e-CRM yang diusulkan diharapkan dapat dikembangkan kembali oleh pihak Beauty Karlina Salon bertujuan agar dapat meningkatkan loyalitas pasien. b. Agar terlaksananya sistem ini dengan baik, diharapkan adanya proses pelatihan dan kerjasama yang baik pada semua pihak yang terkait dengan Beuaty Karlina Salon.

\section{DAFTAR PUSTAKA}

[1] Rosmawarni, N. Perancangan Sistem Rekomendasi untuk Pengembangan Aplikasi Salon Terpadu Berbasis Android. Jurnal Rekayasa Informasi, 6(1), 2017, pp. 61-70.

[2] Hidayat, R. Sistem Informasi Ekspedisi Barang Dengan Metode E-CRM Untuk Meningkatkan Pelayanan Pelanggan. Sisfotek Global, 4(2), 2014, p. 41-45.

[3] Rosalina, V. et al. Pemodelan Eletronic Customer Relationship Management (E-CRM) Pada Rumah Sakit. Jurnal PROSISKO, 5(2), 2018, pp. 87-91.

[4] Abdurrahman, J. Hamdani, D. and Novantara, P. Impelementasi Customer Relationship Management (CRM) Pada Penerimaan Siswa Baru (Studi Kasus di Pondok Pesantren Darussalam Kabupaten Garut). Jurnal Nuansa Informatika, 12(1), 2018, pp. 29-36.

[5] Babar, M., \& Saitakela, M. (2019). Implementasi Customer Relationship Management (CRM) Pada Klinik Valerie Beauty. Journal Informatic Technology And Communication, 3(1), pp. 58-63.

[6] Saeger, A. de, \& Feys, B. (2015). The Ishikawa Diagram: Identify problems and take action (First Edit).

[7] Wida Fridayanthie, E. and Mahdiati, T. (2016) 'Rancang Bangun Sistem Informasi Permintaan ATK Berbasis Intranet (Studi Kasus: Kejaksaan Negeri Rangkasbitung)', Jurnal Khatulistiwa Informatika, 4(2), pp. 126-138. 